NEW APPLIANCES

\title{
Estimation of Clubbing by Analysis of Shadowgraph
}

Dr. Donald Bentley, late senior houseofficer, the London Hospital, London E.1, and Mr. JoHN ClINE, medical technologist/engineer, write: A vast quantity of literature has been produced on the subject of finger-clubbing. Much has been written about possible aetiological factors and conditions in which clubbing is seen. Relatively little, however, has been reported on what is undoubtedly one of the most important aspects of this topic - namely, a rapid, simple to operate yet inexpensive technique of clubbing measurement-and few have attempted to equate it precisely.

We decided to create a machine which by reflection would produce a magnified image of the finger on a screen. Detailed examination of the shadow could then be made. The present device is a cylindrical unit, the casing of which is made of nylon, with an oblique hood projecting beyond the screen (Fig. 1). The visor and casing are built on two metal rings. A square tin containing a 4.5-volt battery forms a platform and also acts as ballast. On the top of the device is a

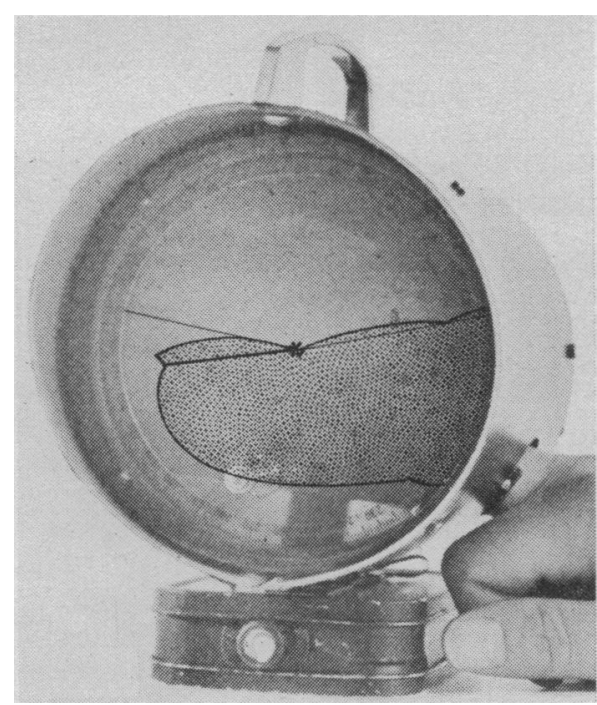

FIG. 1.-Clubbing shadowgram.

handle. At the rear end a small control enables the light bulb to be repositioned, as required, by means of a nylon drive cord. The variable light source raises and lowers the profile of the finger and so brings it into alignment with the datum point on the screen. This is necessary because the cuticle has to be positioned at the fixed point and fingers of differing dimensions need to be accommodated. The finger being studied enters through a hole at the side of the uni and rests on a fixed aluminium cradle.

The screen is composed of two transparent discs. One is a protractor calibrated 0 to 360 degrees with a line printed along a single radius. A second posterior noncalibrated disc has a similar line to denote the radial plane. When both radii meet in the horizontal plane the protractor will be reading 180 degrees. Between the two screens is a free circular piece of tissue paper. The unscaled screen is connected to the front protractor by a small piston, with a spring seating, which enters through a small aperture into the second screen. If the spring is not depressed the anterior screen rotates alone, but when the piston is pushed into the opening in the adjacent one both revolve together. The clear light bulb results in a magnified image being formed. Where the device is to be used for fingerjoint measurement, as it can with an alternative calibration system, a frosted bulb will project a non-magnified profile, and so the true dimensions can be recorded.

After having positioned the finger on to the support the datum point is located at the cuticle by the control described above. Then the radial line on the first screenthat is, the protractor-is moved so that it passes through the distal digital crease (Fig. 2). The radius on the second screen, also arising from the point at the cuticle, passes

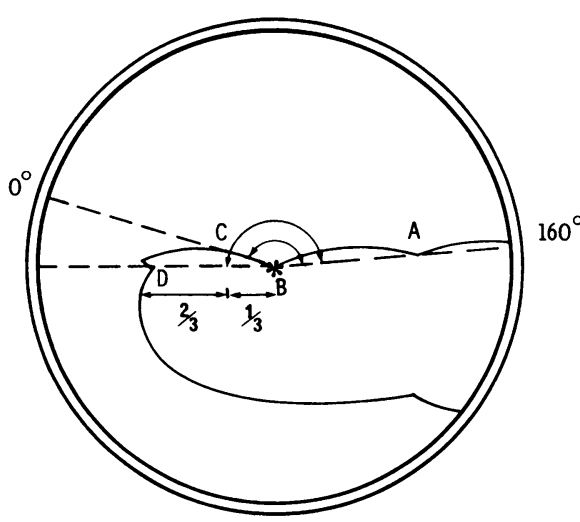

FIG 2.-Construction of profile and hyponychial angles. $A=$ Distal digital crease. $\quad B=$ Datum point to fingertip. $D=H y p o n y c h i u m$ (thickened stratum corneum of epidermis lying under free edge of nail). $\mathrm{ABC}=$ Profile angle. $\mathrm{ABD}=$ Hyponychial angle.

either to a point one-third of the distance along the nail distally, or to the hyponychium. In the former case the profile angle is being measured and in the latter the hyponychial angle. Both can be read direct from the encircling protractor. With a slightly modified system of calibration, finger-joint swelling could be readily studied, the extent of the arthritis being recorded in the anteroposterior and lateral planes.

Such a device might aid rheumatologists in assessing various treatments and so supplement the jeweller's ring technique (Hart and Boardman, 1963). A larger instrument built on the same principle would enable the precise range of movement of a member to be assessed during rehabilitation of a diseased joint. Almost every joint could be brought within the scope of such examination. Where clubbing is concerned there is no doubt that a quantitative expression would be useful (Cudkowitz and Wraith, 1957; Stavem, 1959). Several criteria can be studied, including: (1) increase in volume of finger-tip (plethysmography was described as the "poorest discriminator" in one objective study by Regan, Tagg, and Thomson, 1967)-it was Caelius Aurelianus, circa A.D. 200, who first drew attention to this measurement as an important feature on clubbing (Ebstein, 1907); (2) longitudinal curvature of the nail (Stavem, 1959); (3) profile sign (the "essential angle," Lovibond, 1938; Fischer, Singer, and Feldman, 1964); and (4) hyponychial angle (the "best discriminator," Regan et al., 1967).

The hyponychial angle may be the most satisfactory assessor, since it combines to some extent the measurement of curvature and profile angle. Methods involving digital casts (Mellins and Fishman, 1966) are not practicable for a busy clinician. This can be said also of Cudkowitz and Wraith's (1957) technique of estimating water displacement. The device designed by Stavem (1959) (the octagonal brass disc) is of bedside use, but it assesses only the longitudinal curvature. There are obvious disadvantages in calculating the angles from photographs.

The principle of studying a reflected and magnified image as a shadowgram has many potentialities in medicine and surgery. Nodules, tumours, haemangiomas, and other masses which need to be periodically supervised can have their depth and other dimensions recorded by a shadowgraphic technique. Such examples of the application of this fundamental conception are countless.

The shadowgram described here is both easy to operate and accurate within a few degrees. After minimal practice it can be used at the bedside with little inconvenience and no discomfort to the patient. It has been used on a number of patients both with and without clubbing, and it was satisfying to express by a quantitative means the severity of this sign. It might prove of interest to record the degree of clubbing in the various conditions in which it manifests through phases of a disease. Our instrument offers a swift and easy means of further study into this complex problem.

The clubbing shadowgram is to be manufactured by Schuco International London, Ltd. (patent pending). We wish to cxpress our gratitude to Professor A. E. Read, Dr. F. D. Hart, and Mr. J. R. Belcher for their encouragement and guidance.

\section{REFERENCES}

Cudkowitz, L., and Wraith, D. G. (1957). British Fournal of Tuberculosis and Diseases of the Chest, 51, 14

Ebstein, E. (1907). Deuts:hes Archiv für klinisches Medizin, 89, 67.

Fischer, D. S., Singer, D. H., and Feldman, S. M (1964). Medicine, 43, 459.

Hart, F. D., and Boardman, P. L. (1963). British Medical fournal, 2, 965.

Lovibond, J. L. (1938). Lancet, 1, 363.

Mellins, R. B., and Fishman, A. P. (1966). Circulation, 33, 143 . Regan. G. M., Tagg, B., and Thomson, M. L.
(1967). Lancet, 1, 530.

Stavem, P. (1959). Lancet, 2, 7. 